\title{
The effectiveness of workplace dietary interventions: protocol for a systematic review and meta-analysis
}

\author{
Sarah A. Smith ${ }^{1,2^{*}}$, Amelia A. Lake ${ }^{1,2}$, Carolyn Summerbell ${ }^{1,2}$, Vera Araujo-Soares ${ }^{1,3}$ and Frances Hillier-Brown ${ }^{1,2}$
}

\begin{abstract}
Background: The lack of evidence of the role of workplaces as settings for behaviour change delivery and the failure to recognise and address the complexity of the work environment has been acknowledged. This systematic review and meta-analysis will identify the effectiveness of dietary interventions in the workplace facilitating an understanding of what works, why and how by identifying key components of and examining the theoretical models of behaviour change underpinning successful dietary interventions in the workplace.

Methods/design: We will conduct searches in MEDLINE, EMBASE, CINAHL, PsycINFO, CENTRAL and PubMed for studies that assess dietary interventions based within workplace settings in any country, of any length of time or duration of follow-up. We will include all randomised controlled trials (RCTs), non-randomised controlled trials (NRCTs), controlled before-after studies (CBAs) and interrupted time series (ITS) studies with a control group. Risk of bias of included studies will be assessed using a tool adapted from the Cochrane Public Health Review Group's recommended Effective Public Health Practice Project Quality Assessment Tool for Quantitative Studies. Meta-analysis will be conducted if appropriate, or a narrative synthesis will be conducted following the ESRC Narrative Synthesis Guidance.

Discussion: This paper outlines the study protocol for a systematic review and meta-analysis that will identify, critically appraise, and summarise the relevant evidence on the effectiveness and implications of interventions to promote healthier dietary behaviours in the workplace. This review will give an overview of the evidence and provide a guide for development of interventions promoting dietary behaviour change in workplaces.
\end{abstract}

Systematic review registration: PROSPERO CRD42015015175

Keywords: Workplace, Diet, Nutrition, Intervention, Health promotion, Systematic Review, Meta-analysis

\section{Background}

The increasing prevalence of adults who are overweight and obese is continuing to pose a major global public health problem. Recent WHO global estimates show that overall, about $13 \%$ of the world's adult population aged 18 years and over (11 \% of men and $15 \%$ of women) were obese in 2014, and $39 \%$ of adults (38\% of men and $40 \%$ of women) were overweight [1]. In the UK, the proportion of obese adults has increased to $26 \%$ in men and $23.8 \%$ for women between 1993 and

\footnotetext{
*Correspondence: sarah.smith@durham.ac.uk

${ }^{1}$ Fuse, UKCRC Centre for Translational Research in Public Health, Newcastle, UK

${ }^{2}$ School of Medicine, Pharmacy and Health, Durham University, Queen's

Campus, Stockton-On-Tees, UK

Full list of author information is available at the end of the article
}

2013 [2]. In the UK in 2010, on average, obese people took four extra sick days per year [3] which for the average company equates to more than $£ 126,000$ a year in lost productivity [4]. Estimates of the indirect costs of obesity such as loss of productivity in 2001 were $£ 15.8$ billion [5]. Coupled with the rise in obesity-associated comorbidities, the financial cost of obesity is continuing to rise.

In response to the rising global trend in obesity and overweight, WHO has developed the "Global Action Plan for the prevention and control of non-communicable diseases 2013-2020" [1] which aims to build on the WHO Framework Convention on Tobacco Control and the WHO Global Strategy on Diet, Physical Activity and Health. The plan will contribute to nine global targets to 
be attained in 2025, including a halting of the global obesity rates to those of 2010. There is a global need to develop and evaluate dietary interventions conducted in various settings to address the 'globesity' problem $[6,7]$. Amongst others, the workplace environment has been identified as an ideal setting for health interventions [8] in which to tackle diet and lifestyle behaviours [9]. Workplace interventions have the potential to target a large proportion of the adult population particularly as those in employment can spend up to two thirds of their day at work [10-14]. Furthermore, prevalence of overweight and obesity varies by age, with higher prevalence in older age groups amongst both men and women [1]. With an aging population and a greater proportion of people working past retirement age, the positive impact of workplace interventions could be seen across the working lifespan. The scope of workplace interventions to address overweight and obesity is great, with the potential to impact on individuals across society; however, the greatest benefit may be for those in full-time employment who can access onsite catering and interventions which are typically delivered during daytime working hours. Those who work part-time, particularly women, or during evenings and during the night may not have the same access as fulltime workers; therefore, there is the risk of creating health inequalities across organisations. There is a need for more studies of the effectiveness of interventions in reducing inequalities in obesity for both men and women, with an emphasis on macro- or organisational-level interventions, such as workplaces, that have the potential to address the entire gradient [15].

Despite the obvious potential of workplace interventions targeting health behaviours, few UK-based workplace intervention studies have been published. Fewer still focus on the practicalities and implications when running an intervention within the workplace setting [16], and there is still uncertainty about the effectiveness of dietary interventions in the workplace. A number of workplace-based interventions have attempted to change dietary behaviour [17-21]. Techniques such as education, counselling and alterations to the physical environment of the workplace have all been used in an attempt to modify dietary intake $[22,23]$. A number of systematic reviews into workplace interventions have shown that environmental modifications and education in relation to diet, physical activity, and lifestyle factors have, in general, lead to moderate improvement in dietary intake [24-26]. However, the lack of evidence regarding the role of worksites and in particular the failure of many interventions to recognise and address the complexity of the work environment has been acknowledged.

This systematic review of published controlled trials will identify, critically appraise and summarise the relevant evidence on the effectiveness and implications of interventions to promote healthier dietary behaviours in the workplace. Furthermore, this review will facilitate an understanding of what works, why and how by identifying key components of and examining the theoretical models of behaviour change underpinning successful dietary interventions in the workplace. The findings will provide a guide for the development of future interventions and research into tackling workplace obesogenic environments and promoting positive dietary behaviour change in workplaces.

\section{Objectives}

The objectives are as follows:

1. To identify what workplace-based interventions are effective at reducing energy intake, reducing fat intake, reducing salt intake and reducing consumption of sugar sweetened beverages and/or sweets.

2. To identify what workplace interventions are effective at increasing fruit and/or vegetable consumption and/or increasing fibre intake.

3. To identify what workplace interventions are effective at reducing and/or controlling food portion size.

4. To explore if some subgroups of the population are more responsive to such interventions (for example, older versus younger employees, men versus women, shift workers versus non-shift workers, night shift workers, manual versus professional, socioeconomic status, ethnicity).

5. To explore if changes in weight, body mass index, body composition and/or waist circumference are observed in response to dietary interventions in the workplace.

6. To explore if changes in employee wellbeing, productivity and absenteeism are observed in response to dietary interventions in the workplace.

7. The interventions included in this systematic review will be analysed, as much as possible, on the basis of the behaviour change techniques used.

\section{Methods/design}

Prior to conducting the review, we carried out a scoping search to ensure adequate sensitivity of the search strategy. The search was piloted in MEDLINE (searched 27 April 2015) and resulted in 2069 hits. Furthermore, five indicator papers identified prior to running the search were included in the results [27-31] suggesting we would find sufficient evidence from controlled studies to meet our objectives. Therefore, we will only include evidence from randomised controlled trials (RCTs), nonrandomised controlled trials (NRCTs), controlled beforeafter studies (CBAs) and interrupted time series (ITS) studies with a control group. Cochrane Effective Practice and Organisation of Care (EPOC) [32] study design criteria 
will used to identify studies. The review is registered with PROSPERO (International prospective register of systematic reviews) at the National Institute for Health Research and Centre for Reviews and Dissemination (CRD) at the University of York (registration number CRD42015015175) and will be reported in accordance with the PRISMA [33, 34] statement and MECIR standards [35]. Additional files show the PRISMA statement and checklist in more detail [see Additional file 1 and Additional file 2].

\section{Population}

The studied population will be adults of all gender, socioeconomic status and nationality, with a mean age of 16 or older who are employed at the worksite.

\section{Interventions}

The review will examine interventions that will target dietary behaviours that are based in any workplace in any country. The types of interventions expected to be found include, but are not restricted to, educational, environmental changes, counselling and food provision. There will be no restriction on the length of the intervention, but only studies with duration (intervention plus followup) of 4 weeks or over will be included. This criterion is set so as to be as inclusive as possible of studies, and to study the short-term as well as long-term effects of interventions. Workplace dietary interventions of 4 weeks have been shown to be effective at changing behaviour and sometimes resulting in weight change [36-39].

\section{Comparator}

Studies with a comparator will be included in the review. There will be no restrictions on the type of comparator used in the study.

\section{Outcomes}

Studies will be included if they have at least one primary outcome of interest. This includes a dietary intake outcome (change in vegetable consumption ( $\mathrm{g}$ or SV). change in fruit consumption ( $\mathrm{g}$ or SV), change in fruit and vegetable consumption ( $\mathrm{g}$ or SV), change in consumption of sugar sweetened beverages $(\mathrm{g})$, change in consumption of 'other foods', catering/food sales data) and a nutritional intake outcome (change in energy intake (kcal), change in fat intake $(\mathrm{g})$, change in salt intake (g), change in fibre intake ( $\mathrm{mmHg})$, change in portion size ( $g$ or SV), change in food environment). The review will include various methods of outcome measurement, for example, but not restricted to, self report, researcher observations, photographs of food portions and weighed intake.

Data on related secondary outcomes (such as change in weight $(\mathrm{kg})$, change in body mass index $\left(\mathrm{kg} / \mathrm{m}^{2}\right)$, change in body composition, change in waist circumference $(\mathrm{cm})$ and improvement in productivity and reduction in absenteeism) will also be extracted from those studies which have a primary outcome. Where reported, we will include data on differential effects between specific populations (for example, older versus younger employees, men versus women, shift workers versus non-shift workers, night shift workers, manual versus professional, socioeconomic status, ethnicity).

\section{Literature searching}

We will run one overarching search (amended to suit syntax requirements) to identify studies of relevance, and the electronic databases to be searched include MEDLINE (Ovid), EMBASE (Ovid), CINAHL (Ebscohost), PsycINFO (Ebscohost), CENTRAL (Cochrane Central Register of Controlled Trials) and PubMed. An additional file shows the search strategy in more detail [see Additional file 3]. All databases will be searched from inception to present day as of 11 May 2015.

\section{Searching other sources}

Reference lists of included studies and relevant systematic reviews will be searched for any additional papers not picked up by our database searches. Known topic experts in a variety of countries will be contacted via email to enquire of any additional interventions they are aware of that may be of relevance to this review.

\section{Study selection and screening}

A reviewer (SS) will independently screen the titles and abstracts to identify those that are relevant and meet the inclusion criteria. A second reviewer (FH, AL) will screen a random $10 \%$ sample of titles and abstracts. Full texts of each included paper will be obtained and reviewed by one reviewer (SS) to determine which papers to include in the review, based on the inclusion and exclusion criteria. A second reviewer (FH, AL) will screen a random $10 \%$ sample of the full texts. In the situation where first and second reviewers cannot decide on inclusion or exclusion of a title/abstract/paper, a third reviewer (CS, VA) will be consulted to achieve consensus.

\section{Data extraction}

Data extraction will be conducted independently for each study by two reviewers (SS, FH, AL, VA, CS). Electronic data extraction forms (pre-established to ensure consistency and accuracy between reviewers) will be manually completed and will include details on study design, participant characteristics, intervention design, intervention duration, study methods, study outcomes, theory underpinning intervention design [40] (utilising the Behaviour Change Wheel [41] and the Nuffield Intervention Ladder [42]), economic cost (purchasing patterns, productivity, absenteeism), funding source and 
quality assessment. To improve the usefulness of the review findings for policy decision making, every attempt will be made to report cost and cost-effectiveness, study characteristics, and generalisability of the findings [43]. Any discrepancies will be resolved by discussion between the two reviewers, and if a decision is not met, a third reviewer will be consulted to reach consensus. The data extraction form will be piloted using a sample of studies and amendments made if required, then a second phase of pilot testing conducted.

\section{Assessment of risk of bias (quality) in included studies}

To assess the quality of each study, a tool adapted from the Cochrane Public Health Review Group's recommended Effective Public Health Practice Project Quality Assessment Tool for Quantitative Studies [44] will be used. The tool includes representativeness of study samples, randomisation, comparability of baseline groups, credibility of data collection tools, attrition rate and attributability to the intervention. As before, any discrepancies will be resolved by discussion between the two reviewers, and if a decision is not met, a third reviewer will be consulted to reach consensus.

\section{Data analysis and synthesis}

We will report our findings in accordance with PRISMA guidelines [33, 34]. A narrative synthesis is planned and will be conducted following the ESRC Narrative Synthesis Guidance [45], but if more than one study is included and the studies are adequately similar in terms of study populations, interventions comparators and outcome investigated, it is intended that a meta-analysis will be preformed. Data synthesis will be carried out in Review Manager (Cochrane Collaboration Software), and both continuous and dichotomous data will be analysed. If high heterogeneity does not exist, we will carry out fixed-effect analysis. If important heterogeneity exists, we will carry out random-effect analysis.

\section{Analysis of subgroups or subsets}

If there are sufficient data, a sub-group analysis will be conducted. Subgroups proposed are interventions conducted in different workplaces, different occupations (manual, professional), various types of dietary interventions (including but not limited to increased fruit and/or vegetable consumption, portion size control, environmental changes), age (less than 30 years and more than 30 years), gender (men versus women), shift workers versus non-shift workers, professional versus manual workers, socioeconomic status and ethnicity.

\section{Discussion}

This review aims to summarise the evidence on the effectiveness of interventions targeting dietary intake in workplaces. It will explore if, and how, factors such as age, gender, socioeconomic status, ethnicity, working patterns and job hierarchy moderate the effects of the interventions. It will also explore if, and how, dietary workplace interventions impact health in terms of changes in body weight and/or body composition and impact worker productivity and absenteeism rates. The review will describe the included interventions in terms of how they are designed, implemented and delivered as well as attempt to discuss the policy and practice implications of the findings, which will be useful in guiding future development of interventions and research into tackling workplace obesogenic environments and promoting positive dietary behaviour change in workplaces.

\section{Additional files}

\section{Additional file 1: PRISMA checklist. The full PRISMA statement checklist for systematic reviews. (PDF $562 \mathrm{~kb}$ ) \\ Additional file 2: PRISMA flow diagram. The full PRISMA statement flow diagram for systematic reviews. (PDF $332 \mathrm{~kb}$ )}

Additional file 3: Search strategy. The complete MEDLINE version of the search strategy. (PDF 281 kb)

\section{Abbreviations}

CENTRAL: Cochrane Central Register of Controlled Trials; CINAHL: Cumulative Index to Nursing and Allied Health Literature; CRD: National Institute for Health Research and Centre for Reviews and Dissemination, York; Ebscohost: provides access to bibliographic databases designed for research; EMBASE: Excerpta Medica database; EPOC: Cochrane Effective Practice and Organisation of Care; ESRC: The Economic and Social Research Council; Fuse: the Centre for Translational Research in Public Health; MECIR: Methodological Expectations of Cochrane Intervention Reviews; MEDLINE: Medical Literature Analysis and Retrieval System Online; Ovid: provides access to online bibliographic databases and academic journals; PRISMA: Preferred Reporting Items for Systematic Reviews and Meta-Analyses; PROSPERO: International prospective register of systematic reviews; PsycINFO: a database of abstracts of literature in the field of psychology; PubMed: a free search engine for literature; UKCRC: UK Clinical Research Collaboration; WHO: World Health Organisation.

Competing interests

The authors declare that they have no competing interests.

\section{Authors' contributions}

SS assisted in the conception of the study idea, the study design, the development of methods and the management of the study and drafted the manuscript. FH assisted in the conception of the study idea, the study design, the development of methods and the management of the study and helped to draft the manuscript. AL assisted in the conception of the study idea and the study design and helped draft the manuscript. CS and VA assisted in the conception of the study idea and have provided critical comments on drafts of the manuscript. All authors have approved the final version of this article and agree to be accountable for all aspects of the work.

\section{Acknowledgements}

The authors gratefully acknowledge the Medical Research Council for fully funding SS as a PhD student via Fuse, the Centre for Translational Research in Public Health. 


\section{Funding}

SS is fully funded by the Medical Research Council via Fuse as a PhD student, and AL is partly funded as a member of Fuse, the Centre for Translational Research in Public Health (www.fuse.ac.uk). Fuse is a UK Clinical Research Collaboration (UKCRC) Public Health Research Centre of Excellence. Funding for Fuse comes from the British Heart Foundation, Cancer Research UK, Economic and Social Research Council, Medical Research Council, and the National Institute for Health Research, under the auspices of the UKCRC, and is gratefully acknowledged. The views expressed in this paper do not necessarily represent those of the funders or UKCRC. The funders had no role in study design, data collection and analysis, decision to publish, or preparation of the manuscript.

\section{Author details}

'Fuse, UKCRC Centre for Translational Research in Public Health, Newcastle, UK. ${ }^{2}$ School of Medicine, Pharmacy and Health, Durham University, Queen's Campus, Stockton-On-Tees, UK. ${ }^{3}$ Institute of Health and Society, Newcastle University, Newcastle-upon-Tyne, UK.

\section{Received: 13 November 2015 Accepted: 27 January 2016}

\section{Published online: 03 February 2016}

\section{References}

1. WHO, Obesity and overweight Fact sheet N³11, WHO (2015). Available from http://www.who.int/mediacentre/factsheets/fs311/en/ [Accessed $8^{\text {th }}$ September 2015]

2. Lifestyles Statistics Team, Health and Social Care Information Centre, Statistics on Obesity, Physical Activity and Diet: England 2015. Available from www.hscic.gov.uk. [Accessed 30 ${ }^{\text {th }}$ March 2915]

3. Harvey SB, Glozier N, Carlton O, Mykletun A, Henderson M, Hotopf M, et al. Obesity and sickness absence: results from the CHAP study. Occup Med. 2010;60:362-36.

4. National Institute of Health and Clinical Excellence (NICE) local government briefings, Workplace Health (2012) http://publications.nice.org.uk/lgb2 [Accessed 30th March 2015]

5. Tackling obesities: future choices_-project report (2nd Ed). London: Foresight Programme of the Government Office for Science 2007 cited in Morgan E. and Dent M. The economic burden of obesity. Oxford: National Obesity Observatory, 2010.

6. Craig P, Dieppe P, Macintyre S, Michie S, Nazareth I, Petticrew M. Developing and evaluating complex interventions: the new Medical Research Council guidance. Public health England (PHE). BMJ. 2008;33:a1655-a1655.

7. National Institute of Health and Clinical Excellence (NICE) behaviour change at population, community and individual levels (Public Health Guidance 6) http://www.nice.org.uk/Guidance/PH6 NICE, London (2007) [Accessed 27th March 2015

8. Lake AA, Rugg-Gunn AJ, Hyland RM, Wood CE, Mathers JC, Adamson AJ Longitudinal dietary change from adolescence to adulthood: perceptions, attributions and evidence. Appetite. 2004:42:255-63.

9. Black C. Working for a healthier tomorrow, Dame Carol Black's Review of the health of Britain's working age population. 2008

10. Department of Health. Choosing health: making healthy choices easier. London: Department of Health; 2004.

11. Pratt CA, Fernandez ID, Stevens VJ. Introduction and overview of worksite studies. Obesity. 2007;15:1S-3.

12. Zapka J, Lemon SC, Estabrook BB, Jolicoeur DG. Keeping a step ahead: formative phase of a workplace intervention trial to prevent obesity. Obesity. 2007;15 Suppl 1:27S-36.

13. Chu C, Breucker G, Harris N, et al. Health-promoting workplaces - international settings development. Health Promot Int 2000;15(2):155-67.

14. WHO. Diet, nutrition and the prevention of chronic diseases. Report of a Joint WHO/FAO Expert Consultation, Geneva: WHO; (1991).

15. Hillier-Brown FC, Bambra CL, Cairns J-M, Kasim A, Moore HJ, Summerbell CD. A systematic review of the effectiveness of individual community and societal-level interventions at reducing socio-economic inequalities in obesity among adults. Int J Obes. 2014;38:1483-90. doi:10.1038/ijo.2014.75.

16. WHO. Diet, nutrition, and the prevention of chronic diseases: report of a joint WHO/FAO expert consultation. WHO (2003)
17. WHO. 2008-2013 Action plan for the global strategy for the prevention and control of noncommunicable diseases, WHO (2008)

18. Verweij L, Proper K, Weel A, Hulshof C, van Mechelen W. Design of the Balance@Work project: systematic development, evaluation and implementation of an occupational health guideline aimed at the prevention of weight gain among employees. BMC Public Health. 2009;9:461.

19. Beresford SA, Shannon J, McLerran D, Thompson B. Seattle 5-a-Day Work-Site Project: process evaluation. Health Educ Behav. 2000;27:213-22.

20. Elliot DL, Goldberg L, Kuehl KS. The PHLAME (Promoting Healthy Lifestyle: Alternative Models' Effects) firefighter study: outcomes of two models of behaviour change. J Occup Environ Med. 2007:49:204-13.

21. Engbers LH, van Poppel MN, Chin AP, van Mechelen W. The effects of a controlled worksite environmental intervention on determinants of dietary behaviour and self-reported fruit, vegetable and fat intake. BMC Public Health. 2006:6:253.

22. Sorensen G, Stoddard A, Peterson K, Cohen N, Hunt MK, Stein E, et al. Increasing fruit and vegetable consumption through worksites and families in the treatwell 5-a-day study. Am J Public Health. 1999;89:54-60.

23. Lassen A, Thorsen AV, Trolle E, Elsig M, Ovesen L. Successful strategies to increase the consumption of fruits and vegetables: results from the Danish 6 a day. Work-site Canteen Model Study. Public Health Nutr. 2004;7:263-70.

24. Mhurchu CN, Aston LM, Jebb SA. Effects of worksite health promotion interventions on employee diets: a systematic review. BMC Publ Health. 2010;10(1):62-9.

25. Maes L, Van Cauwenberghe E, Van Lippevelde W, et al. Effectiveness of workplace interventions in Europe promoting healthy eating: a systematic review. Eur J Public Health. 2012;22(5):677-83.

26. Geaney F, Kelly C, Greiner BA, Harrington JM, Perry IJ, Beirne P. The effectiveness of workplace dietary modification interventions: a systematic review. Prev Med. 2013;57(5):438-47. doi:10.1016/j.ypmed.2013.06.032. Epub 2013 Jul 11

27. Steenhuis I, Van Assema P, Van Breukelen G, Glanz K, Kok G, De Vries H. The impact of educational and environmental interventions in Dutch worksite cafeterias. Health Promot Int. 2004;19(3):335-43.

28. Braeckman L, De Bacquer D, Maes L, De Backer G. Effects of a low-intensity worksite-based nutrition intervention. Occup Med. 1999:49(8):549-55.

29. Holdsworth M, Raymond NT, Haslam C. Does the heartbeat award scheme in England result in change in dietary behaviour in the workplace? Health Promot Int. 2004;19(2):197-204.

30. Lassen AD, Beck A, Leedo E, Andersen EW, Christensen T, Mejborn H, et al. Effectiveness of offering healthy labelled meals in improving the nutritional quality of lunch meals eaten in a worksite canteen. Appetite. 2014;75:128-34. doi:10.1016/j.appet.2013.12.005. Epub 2013 Dec 25.

31. Christensen JR, Overgaard K, Carneiro IG, Holtermann A, Sogaard K. Weight loss among female health care workers- a 1-year workplace based randomized controlled trial in the FINALE-health study. BMC Public Health. 2012;12:625.

32. What study designs should be included in an EPOC review and what should they be called? [https://epoc.cochrane.org/sites/epoc.cochrane.org/ files/uploads/EPOC\%20Study\%20Designs\%20About.pdf]. [Accessed $25^{\text {th }}$ March 2015]

33. Moher D, Liberati A, Tetzlaff J, Altman DG. The PRISMA Group: Preferred reporting items for systematic reviews and meta-analyses: the PRISMA statement. BMJ. 2009;339:b2535.

34. Welch V, Petticrew M, Tugwell $P$, Moher D, O'Neill J, Waters E, et al. PRISMA-equity 2012 extension: reporting guidelines for systematic reviews with a focus on health equity. PLoS Med. 2012;9:e1001333.

35. Chandler J, Churchill R, Higgins J, Lasserson T, Tovey D. Methodological standards for the conduct of new Cochrane Intervention Reviews Version 2.3 (2013). Methodological Expectations of Cochrane Intervention Reviews (MECIR)

36. Byers T, Mullis R, Anderson J, et al. The costs and effects of a nutritional education program following work-site cholesterol screening. Am J Public Health. 1995:85(5):650-5.

37. Armitage $\mathrm{CJ}$, Conner M. Efficacy of a minimal intervention to reduce fat intake. Soc Sci Med. 2001;52(10):1517-24.

38. Irvine AB, Ary DV, Grove DA, Gilfillan-Morton L. The effectiveness of an interactive mulitmedia program to influence eating habits. Health Educ Res. 2004:19(3):290-305.

39. Aldana SG, Greenlaw RL, Diehl HA, Salberg A, Merrill RM, Ohmine S. The effects of a workplace chronic disease prevention program. J Occup Environ Med. 2005;47(6):558-64. 
40. Michie S, Prestwich A. Are interventions theory-based? Development of a theory coding scheme. Health Psychol. 2010; 29 (1): 1-8 (8).

41. Michie S, van Stralen MM, West R. The behaviour change wheel: a new method for characterising and designing behaviour change interventions. Implement Sci. 2011;6:42.

42. Nuffield Council on Bioethics, Public Health: ethical issues, 2007 [http:// nuffieldbioethics.org/wp-content/uploads/2014/07/Public-health-ethicalissues.pdf] [Accessed $25^{\text {th }}$ March 2015]

43. Kite J, Indig D, Mihrshahi S, Milat A, Bauman A. Assessing the usefulness of systematic reviews for policymakers in public health: a case study of overweight and obesity prevention interventions. Prev Med. 2015;81:99-107.

44. Thomas, H. Quality Assessment Tool for Quantitative Studies; Effective Public Health Practice Project, McMaster University: Hamilton, ON, Canada, 2003 [http://www.ephpp.ca/PDF/Quality\%20Assessment\%20Tool_2010_2.pdf] [Accessed 25 $5^{\text {th }}$ March 2015].

45. Popay J, Roberts H, Sowden A, Petticrew M, Arai L, Rodgers M: Guidance on the conduct of narrative synthesis in systematic reviews. Lancaster: ESRC Research Methods Programme; 2006.

Submit your next manuscript to BioMed Central and we will help you at every step:

- We accept pre-submission inquiries

- Our selector tool helps you to find the most relevant journal

- We provide round the clock customer support

- Convenient online submission

- Thorough peer review

- Inclusion in PubMed and all major indexing services

- Maximum visibility for your research

Submit your manuscript at www.biomedcentral.com/submit
Biomed Central 